\title{
Inhibición, la causa del sufrimiento según Abhinavagupta
}

\section{Inhibition: The Cause of Suffering According} to Abhinavagupta

ÓSCAR FIGUEROA

Centro Regional de Investigaciones Multidisciplinarias

UniversidAd NACiONAL AUTÓNOMA DE MÉXico | México

Contacto: figueroa@crim.unam.mx

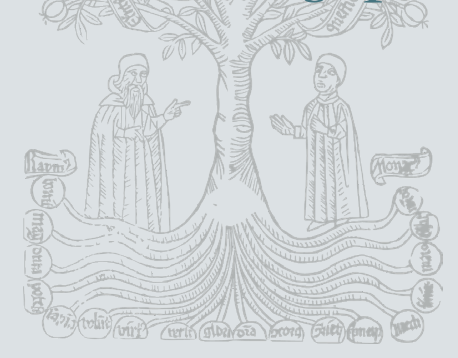

\section{Resumen}

Este artículo estudia la respuesta de Abhinavagupta (siglo XI de nuestra era), uno de los pensadores más originales e importantes de la India clásica, a uno de los temas centrales del pensamiento filosófico y religioso de esa cultura: el sufrimiento. Con ese fin, a manera de contextualización, se revisan primero los ideales que enmarcan el problema del sufrimiento en la tradición canónica india, notablemente las categorías dicotómicas pureza-impureza, y a continuación se resume la crítica a dichos valores emprendida por el movimiento religioso marginal conocido como Tantra, al que perteneció, en sus fases más tardías, el propio Abhinavagupta. El análisis de la respuesta específica de Abhinavagupta presta particular atención al concepto de "inhibición" (sánscrito, śánkā) con base en pasajes clave de su magnum opus, el Tantrāloka, así como del Parātríśikā-Vivarana, otro importante texto suyo, traducidos por primera vez al español directamente del sánscrito. Como muestro, de este análisis se desprende una inusual vindicación del orden finito, el plano del sufrimiento, a condición de que éste sea vivido sin inhibiciones ni dudas, es decir, como la manifestación de una misma conciencia en todas las cosas, incluida la experiencia de lo atroz y lo terrible, y más aún donde no tienen cabida diferencias como puro-impuro, superior-inferior, liberación-esclavitud.
\end{abstract}

Palabras clave: Abhinavagupta, filosofía de la India, Tantra, sufrimiento

\begin{abstract}
This article investigates the response of Abhinavagupta (11th century CE), one of the most important and original thinkers of classical India, to one of the main problems within the philosophical and religious thought of that culture, namely the problem of suffering. To that end, for the sake of contextualization, the ideals framing the problem of suffering in the Indian canonical tradition, especially the opposing values purity-impurity, are first revised; after this, the critique to such ideals as articulated by the marginal religious movement known as Tantra, to whose later strata Abhinavagupta himself belonged, is summarized. The analysis of Abhinavagupta's own response pays particular attention to the concept of "inhibition" (Sanskrit, śankā) and is based on key passages of his magnum opus, the Tantrāloka, as well as his Parātrīíikā-Vivarana, translated into Spanish directly from the original Sanskrit for the first time. As I show, the analysis results in an unusual vindication of the finite order, the realm of suffering, as long as that very order is lived without inhibitions or doubts-that is to say, as the manifestation of one single consciousness in everything, including the experience of evil and the dreadful, and moreover where differences like pure-impure, superior-inferior, liberation-bondage become meaningless.
\end{abstract}

Keywords: Abhinavagupta, Indian philosophy, Tantra, suffering 


\section{La dicotomía pureza-impureza en la India clásica}

Antes de investigar la singular postura de Abhinavagupta ante el problema del sufrimiento, un tema omnipresente en las filosofías y religiones de la India, conviene, a manera de introducción, ofrecer un poco de contexto. Para ello es necesario ir atrás en el tiempo y recordar que uno de los valores distintivos de la India antigua y clásica fue la pureza (śuddhi), contrastada con su opuesto, con aquello que es tenido como impuro (aśuddhi). El contraste opera a varios niveles y en ámbitos diferentes pero interrelacionados: el cósmico-mitológico, a través de la lucha entre el orden y el caos, entre la luz y la oscuridad, entre las fuerzas divinas y las fuerzas demoníacas; el mágico-ritual, a través de una clasificación de las cosas según las categorías propicio y no propicio; el social, a través de un estricto sistema de castas; y el conceptual, a través de modelos verticales, jerárquicos y excluyentes, que sitúan el bien supremo más allá de cualquier contaminación.

Desde luego, en todos estos casos hablamos de discursos dominantes, identificados con el status quo o el establishment, lo que en la India remite sobre todo al orden brahmánico, es decir, a la visión de la casta más alta. Expresado sobre todo en sánscrito, no por casualidad calificada también como la lengua "pura", el discurso canónico en todas estas esferas contiene, por lo tanto, ya sea de manera explícita o implícita, mensajes o enseñanzas sobre lo que debe entenderse por una vida recta o pura, y por supuesto sobre lo que debe evitarse para llevar una vida así. Diríamos que esto vale para cualquier otra cultura antigua, y es cierto. Pero lo que quizás distingue a la India es que ese mensaje a menudo se materializó en un sistema normativo como pocos. Tales códigos se expresan sobre todo en la forma de reglas o, más exactamente, inhibiciones, que fueron internalizadas "en todos los estratos de la sociedad india como ingrediente esencial del proyecto hegemónico" brahmánico, es decir, como mecanismo para garantizar el ideal de pureza (Torella, 2015: 113). El término sánscrito para tales "inhibiciones" es śàikā.

De estas restricciones depende la verdad y el sentido de corrección en cada uno de los planos enunciados (cósmico, ritual, social, conceptual, etcétera), conformando así lo que de manera conjunta se conoce como el dharma, el orden, el deber y la verdad desde la propia perspectiva canónica. Y del dharma depende, por lo tanto y en última instancia, la identidad, lo que soy. Esto significa que soy lo que debo ser, lo que me corresponde ser. Materializado en este sistema de inhibiciones, el ideal de pureza fundamenta la identidad misma. 
Esto demanda, desde luego, una actitud vigilante, pues para su buen funcionamiento, el sistema sobre el que descansa la identidad presupone cierta dosis de ansiedad o temor, acepciones también de la palabra śà̇kā, con mayor razón si se toma en cuenta que ni la pureza ni, por lo tanto, el dharma son estados permanentes, dados de antemano. Más bien operan como principios que es necesario actualizar continuamente en los hechos $\mathrm{y}$, sobre todo, frente a la amenaza ubicua de lo impuro. Lo que debo ser es algo que se construye a cada momento a través de mis actos, tanto físicos como mentales, y de las interacciones con los demás que se derivan de dichos actos. Así pues, como ha señalado Patrick Olivelle (1998), "El propósito de las reglas sobre la impureza no es tanto asegurar un estado de pureza permanente, sino más bien hacer que la gente experimente ansiedad ante la posibilidad de volverse impura" (214).

Esto es tangible, en particular, en los códigos que regulan la casta: a fin de evitar contaminación, cada individuo debe aprender a relacionarse con los demás tomando en cuenta su posición en la sociedad y actualizar ese aprendizaje en cada nueva interacción. Es igualmente tangible en el manejo de sustancias que son vehículos naturales de pureza e impureza - por ejemplo, la dieta, los deshechos corporales, etcétera- y subyace siempre a todo aquello relacionado con la muerte, el paradigma de lo impuro. Otra esfera donde esto se aprecia muy bien es el deseo, la dimensión volitiva de la existencia, representada como un peligro porque, al fomentar formas de vida distintas a las permitidas, amenaza constantemente la identidad y, por 1o tanto, la estabilidad ritual, social y cósmica. El deseo (en sánscrito, kāma) nos empuja a ser alguien que no somos o no debemos ser $\mathrm{y}$, por lo tanto, al menos en potencia, constituye una fuerza subversiva que debe ser inhibida a través de las referidas reglas de convivencia. No en vano, por ejemplo, la mitología describe a los demonios (asuras), los enemigos de los dioses (suras), como seres que "pueden asumir la forma que deseen" (kāmarūpin). Bien pensado, es un don fascinante y al mismo tiempo aterrador: no saber quién es quién, qué es qué. Los demonios representan las fuerzas del caos, pues amenazan el orden solar, el orden de la identidad unívoca, donde nadie puede ser sino lo que debe ser (dharma), no lo que dictan sus deseos, teniendo como modelo el ideal de la pureza.

En general, sobre estos principios descansa el corpus ortodoxo brahmánico, primero en colecciones como las Saṃhitās y los Brāhmaṇas, redactadas antes de la era común, y luego en los códigos legales propiamente, tanto en los Dharmasūtras como en el Mānavadharmaśāstra, compuestos en la transición 
de la era antigua a la era común. La misma visión se repite, al menos como aspiración, en los siglos subsecuentes en toda clase de textos: en los tratados ascéticos, en el Arthaśāstra de Kauțilya, en las dos grandes narrativas del período, el Rāmāyaṇa y el Mahābhārata, y un largo etcétera.

Pero adonde aquí nos interesa llegar es a la influencia de esta visión sobre el discurso filosófico. ¿Cómo se articuló filosóficamente la oposición purezaimpureza, con su respectiva dosis de inhibición? ¿Cómo se expresó filosóficamente, por ejemplo, el conflicto entre el dharma y el deseo, entre la identidad y aquello que la amenaza o pone en duda? De manera amplia, cabe decir que ocurrió a través de una extrapolación de la impureza al orden finito en su conjunto, o lo que los indios llaman, por algo, el samsara: el absurdo ciclo de nacimiento y muerte, el devenir ilusorio y finito que consume y devora una y otra vez, vida tras vida. En contraste, la verdad última, la pureza conceptual, sólo puede hallarse más allá del samsara y alcanzarse a través de una gnosis liberadora centrada en principios como el ser absoluto o brahman (según el modelo ilusionista de escuelas como el Vedānta), el espíritu supremo o puruṣa (según el modelo dualista de escuelas como el Sāñkhya), etcétera. En este esquema, el sufrimiento pertenece, desde luego, al ámbito de la impureza, al samsara, por definición el mundo del deseo. Así, respecto al ideal de pureza, el deseo es una fuerza que convierte la existencia en un reino de insatisfacción y dolor. Ésa fue la verdad a la que arribó, por ejemplo, el Buda el día de su despertar: la verdad del voraz deseo (trṣnāa) como la causa del sufrimiento que define la existencia en el samsara. Sobre ello versa, por ende, su primer sermón:

Y ahora, monjes, ésta es la noble verdad sobre la causa del sufrimiento: el deseo voraz que lleva a la existencia repetida, condicionada [ella misma] por la avidez, por la búsqueda de placer en esto y aquello; es decir, el deseo de placeres sensuales. (Samyuttanikāya, 1884-1904: 5.56.11) ${ }^{1}$

La Bhagavadgìtā, la obra clásica de lo que hoy llamamos hinduismo, nos ofrece otro ejemplo paradigmático al censurar el deseo como estrategia para rescatar la existencia ordinaria, irremediablemente sometida a la actividad. "Abandona todos tus deseos... deshazte del apego al placer" (Bhagavadgitā, 1945: 2.55-56), instruye el dios Kṛ̣na al príncipe Arjuna, al tiempo que lo llama a descubrir en el conocimiento del ser inmortal la solución definitiva a su

\footnotetext{
1 Todas las traducciones del sánscrito, y en este caso del pāli, son mías.
} 
dilema moral: abrazar su deber guerrero a costa incluso de la muerte de seres queridos. La reacción de Arjuna se justifica plenamente: "Oh Kṛ̣ṇa, si, como afirmas, el conocimiento es superior a la acción, entonces ¿por qué me ordenas [cometer] tan terrible acto?" (Bhagavadgītā, 1945: 3.1). Como respuesta, Kṛ̣ṇa articula una vigorosa defensa de la acción, bajo la premisa de que es posible escapar a sus efectos negativos. El secreto está en dar a los actos un valor agregado: no sólo actuar sino actuar correctamente, y el sentido de corrección debe buscarse en la acción desinteresada, "sin deseos" (niṣkāma), con el ritual brahmánico como modelo:

Puesto que la acción es mejor que la inacción, 1leva a cabo las acciones que a ti corresponden [...]. Ahora bien, la acción esclaviza al hombre cuando carece de un fin sacrificial. Por lo tanto, oh Arjuna, lleva a cabo acciones con tal fin, sin deseos [...] Y libre siempre de apego, cumple las acciones que a ti corresponden, pues sólo quien actúa sin apegos alcanza la meta suprema. (Bhagavadgītā, 1945: 3.8-9, 19)

Con ello, Kṛ̣na está pidiendo a Arjuna que aparte sus actos de la teleología del deseo y, en cambio, los reduzca a simple deber por el deber mismo, el dharma puro y llano, entendido como la salvaguarda de la pureza: la identidad pulcra, por la que cada quien es, de nuevo, lo que le corresponde ser, no lo que desea ser.

Ahora bien, la representación de la existencia según la oposición puro-impuro es, desde luego, una representación idealizada, normativa, de la realidad, no la realidad misma. De hecho, en el acto mismo de atenuar y regular, o, en el otro extremo, rechazar y demonizar, el discurso canónico proyecta un entorno de diversidad con amplias zonas de contacto caracterizadas tanto por la aquiescencia como por la tensión, tanto por estrategias de conciliación como por tentativas de emancipación. Los testimonios son muchos y provienen de muy diversos frentes: expresiones populares, el arte literario, el propio discurso religioso y filosófico. En este último ámbito, el filosófico-religioso, varios de esos ejercicios cristalizaron de una forma nueva y potente en lo que se conoce como Tantra, religión tántrica o cultos tántricos, la tradición en la que se inscribe el pensamiento de Abhinavagupta y sobre la que es necesario decir algunas cosas. 


\section{El movimiento tántrico o la vía de la transgresión}

Si algo distinguió a la religión tántrica en el panorama religioso de la India clásica, fue su inusitada exploración de lo impuro como mecanismo para transformar la identidad. Por lo apenas expuesto, esa exploración a menudo se acompañó de una vindicación categórica del deseo sin pasar necesariamente por un acuerdo con el establishment, sino más bien, de ser el caso, a costa suya, es decir, usando como estrategia el propio conflicto de valores e incluso poniendo en duda el ideal de pureza al extremo de la afrenta y la subversión.

Podemos intuir que un movimiento así sólo pudo haber surgido en los márgenes de la cultura brahmánica, ahí donde el sistema de inhibiciones era más frágil. Ello ocurrió entre los siglos V y VI, cuando en el seno de la devoción popular al dios Śiva y a diferentes deidades femeninas, empezaron a propagarse prácticas y doctrinas poco convencionales que cuestionaban la ortopraxis brahmánica y defendían lo impuro como vía religiosa. El fenómeno evolucionó de manera gradual entre los siglos VII y IX, y comprendió varias fases asociadas con diferentes grupos de practicantes. Así, el primero de esos movimientos, el de los Pāśupatas o "seguidores de Paśupati", una advocación de Śiva, agrupó a brahmanes que se veían a sí mismos formando parte de la tradición canónica pese a promover prácticas que se alejaban de las normas sociales, tales como embadurnarse el cuerpo con cenizas de cadáver, cometer actos indecentes y fingir demencia. En fases posteriores, la exploración de estas y otras prácticas se produjo con una mayor conciencia de su marginalidad frente a la ortodoxia. Esta tendencia alcanzó su máxima expresión con el movimiento de los Kāpālikas, así llamados por la práctica de portar cráneos (kāpāla) como parte de su parafernalia distintiva. Esta tradición de ascetas marginales ensalzó más abiertamente el aspecto transgresor de Śiva, y en ese contexto exageró la parafernalia mortuoria, incrementó el contacto con sustancias impuras (alcohol, carne, deshechos corporales, etcétera) y, a nivel doctrinal, articuló una visión más dinámica de la realidad de camino a una integración de lo atemporal y lo finito, un elemento clave de la cosmovisión tántrica que sembró una semilla crítica respecto a la idea de "inhibición" (śañkā) desde una perspectiva no dualista (advaita) radical.

No es aquí, desde luego, el espacio para entrar en detalles. Basta señalar que el talante subversivo de estos movimientos tempranos se expresó sobre todo in actu, a través de acciones rituales y conductas específicas, pero sin un discurso muy elaborado. Esto vale incluso para los primeros usos en estas 
corrientes de la categoría advaita, "no dual", usada para nombrar una actitud consciente de rechazo hacia los valores puro-impuro, pero casi siempre en un contexto ritual o práctico, y rara vez como un posicionamiento teórico o filosófico. Así, en el Mālinīuijaya Tantra, una escritura del siglo VIII, leemos, por ejemplo: "No hay en este mundo pureza ni impureza; lo que uno debe comer o dejar de comer no es algo que merezca discutirse" (Mālinīvijaya Tantra, 1922: 18.74). Más contundente aún, un siglo después, es el testimonio del Vijñānabhairava Tantra: "Lo que los hombres de conocimiento limitado prescriben como impuro es, desde la perspectiva de los devotos de Śiva, puro. De hecho, no hay pureza ni impureza. Así, libre de representaciones mentales, [el yogui] experimenta alegría" (Vijñana Bhairava, 2017: 120).

En un tono similar, pero en el ámbito budista, el Cạ̣damahāroṣaṇa Tantra, ya en el siglo XI, enseña:

Tal como un árbol da abundantes frutos cuando recibe desechos naturales, del mismo modo una persona obtiene el genuino fruto del placer cuando participa de toda clase de sustancias impuras. Para una persona así no hay vejez ni enfermedad ni muerte. Aquel que se consagra a lo impuro, aun sin yoga, alcanza la meta. El experto en yoga no hace distinciones tales como esto puede comerse, esto otro está prohibido comerlo; es correcto hacer esto, esto otro está prohibido hacerlo; esto es deseable, esto otro indeseable. No fantasea con cosas como el mérito y el pecado, el cielo y la liberación. (The Tantra, 2016: 7.6-9).

Fue precisamente entre los siglos IX y XI que expresiones como éstas y, en un sentido más amplio, la experiencia acumulada de varias generaciones de iniciados comenzaron a materializarse en doctrinas no dualistas más elaboradas que ahondaron la reflexión crítica en torno a las ideas de pureza e inhibición, percibidas ahora como postulados esenciales, si bien implícitos, de las tradiciones intelectuales dominantes, incluidas aquellas que se presentaban como no dualistas (notablemente el Vedānta). Al respecto, destacan dos cosas. En primer lugar, la creciente presencia de elementos femeninos, sin duda otra forma de subversión a la luz de la cultura patriarcal india: el dios aparece ahora acompañado o a veces es incluso desplazado por clanes de diosas, concebidas como sus emanaciones o "potencias" (śakti) e imaginadas como creaturas indómitas que presiden sobre los distintos planos de la creación, desde los objetos físicos hasta la actividad sensorial y mental, conformando así el cuerpo cósmico-femenino de la deidad, la manifestación de su poder y soberanía. 
Con ello, los cultos tántricos reconocen como atributo central de la deidad ya no únicamente la pureza trascendente, sino asimismo la omnipotencia inmanente, abriendo las puertas, por un lado, para interpretar el devenir temporal más allá de su asociación exclusiva con el samsara, el ámbito de lo impuro y el sufrimiento, y por el otro, para redefinir la idea misma de no dualidad desde una perspectiva más ambiciosa, sin inhibiciones. El segundo ingrediente que sobresale, íntimamente conectado con el primero, es la tendencia a ver la emancipación o liberación (mukti) como algo compatible con la búsqueda de poderes sobrenaturales (siddhi) y con el disfrute (bhukti) de las fuerzas que entretejen la existencia, concebidas entonces afirmativamente, una importante diferencia con la doctrina ortodoxa. Para ello, el iniciado tántrico debe invocar la presencia avasallante de estas energías, exponerse a ellas, dejarse poseer por ellas y poseerlas, $\mathrm{y}$, a partir de esa experiencia, construirse una nueva identidad, expresada en estados acrecentados de conciencia en los que se experimenta a la deidad en todas las cosas, sin inhibiciones, en lo puro y en lo impuro, en lo superior y en lo inferior, en lo infinito y en lo finito, en la liberación y en el sufrimiento.

Esta visión pronto desbordó su caldo de cultivo original, el culto a Śiva y la diosa, para hacerse sentir en otros credos. Como han señalado los especialistas, la visión tántrica descansa siempre sobre alguna otra religiosidad que le sirve de telón de fondo $\mathrm{y}$, en ese sentido, representa una vertiente al interior de estructuras religiosas más amplias, de las que depende y respecto a las cuales funciona a su vez como complemento (Padoux, 1998: 13). Este hecho enmarca la expansión del Tantra tanto en relación con tradiciones que hoy agrupamos bajo la categoría hinduismo como en el seno de las tradiciones jainista y budista (Sanderson, 2009: 124). Esa expansión comprende además un proceso de recepción e interpretación filosófica que tendrá precisamente en Abhinavagupta uno de sus momentos culminantes.

\section{La (verdadera) causa del sufrimiento según Abhinavagupta}

En efecto, los cultos tántricos adquirieron un perfil más filosófico al interior de la rica tradición exegética que a partir del siglo x los interpretó desde una perspectiva abiertamente no dualista e interiorista, en la que la experiencia de absorción contemplativa acabó por imponerse sobre el complejo aparato 
ritual que solía contener esa experiencia. El más importante de esos exegetas fue Abhinavagupta.

Autor de una vasta obra y uno de los pensadores más originales de la India clásica, Abhinavagupta vivió a finales del siglo x en Cachemira, al extremo noroeste del subcontinente indio. Para entonces, esa región a los pies del Himalaya se había ganado el reconocimiento como una de las grandes capitales intelectuales de la India. Ahí florecieron la teoría poética y teatral; ahí se renovaron disciplinas como la gramática, la lógica y la filosofía del lenguaje; por su parte, en el terreno literario, las innovaciones tanto en estilo como en contenido de figuras como Dāmodaragupta, Bhallața y Ratnākara, y más tarde Somadevabhaț̣a, Kṣemendra y Kalhạ̣a, dieron forma a piezas que hoy pueden considerarse pioneras en sus respectivos géneros; finalmente, en cuanto a la vida religiosa, el valle de Cachemira auspició una asombrosa diversidad y ductilidad, y fue testigo de una explosión de corrientes tántricas. Formado en el entrecruce de todas estas influencias, Abhinavagupta fue un iniciado tántrico muy sui generis, pues estuvo en condiciones de empaparse de la tradición escolástica sánscrita y echar mano, por lo tanto, de numerosas herramientas teóricas (de la lógica a la gramática, de la estética a la retórica) para interpretar el canon revelado a la luz de criterios de verdad más amplios y en diálogo con otras escuelas, entre ellas el budismo.

De acuerdo con esa interpretación, todo lo que nos rodea es la manifestación de la energía creadora de Śiva, de su Śakti, entendida como un poder consciente y libre. Esto significa que todo cuanto existe es la expresión del poder de la conciencia para representarse a sí misma dentro de sí misma. Caracterizada como un principio luminoso, la conciencia es ella siempre más sus contenidos, su propio reflejo. En términos soteriológicos, esto significa, como proponían los primeros iniciados tántricos, que el binomio puro-impuro es un espejismo: puesto que todo es conciencia y nada hay en realidad que condene al individuo, a fin de liberarse del sufrimiento este debe simplemente trascender sus inhibiciones (śan்kā) y abrazar en su propio ser su identidad plena con la divinidad.

Sobre esto, dice Abhinavagupta en su obra principal, el Tantrātoka o Elucidación sobre el Tantra:

Pureza e impureza son categorías que suelen emplearse en las prescripciones brahmánicas. Nuestra tradición, en cambio, ofrece una prescripción especial, cuyo propósito es precisamente suspender la aplicación de las reglas [brah- 
mánicas] entre aquellos que han comprendido a fondo la realidad [...] Y es que incluso si las cosas existieran fuera de la conciencia, la pureza y/o impureza que les atribuimos no pueden ser valores objetivos, como lo es, por ejemplo, su color. En realidad, los valores puro-impuro pertenecen exclusivamente al sujeto y son el resultado de la manera como éste percibe las cosas. (Abhinavagupta, 1918-1938: 4.231-232, 244-246).

En este pasaje, nuestro autor establece claramente que las categorías puro-impuro no describen cualidades inherentes a las cosas, sino que más bien constituyen una proyección del sujeto que las enuncia; remiten a él y a su identidad limitada. Desde luego, esa proyección permite clasificar y controlar la realidad, y a partir de ese control se construyen ciertos ideales y se vuelve posible aspirar a cierto tipo de felicidad, la felicidad basada en la pureza, pero no la libertad más alta ni la más completa, y, por lo tanto, en un sentido profundo, el sufrimiento persiste. Esto significa que los juicios de valor y las restricciones que sustentan el ideal de pureza, lejos de ser la solución, son parte del problema. En un tono más filosófico, al afirmar que pureza e impureza no son valores objetivos "incluso si las cosas existieran fuera de la conciencia", indirectamente, Abhinavagupta nos recuerda que el desmantelamiento de la identidad construida sobre el binomio puro-impuro supone, en última instancia, cuestionar aquellas doctrinas que proponen ver las cosas desde afuera, como si el mundo fuese externo a la conciencia. En efecto, entendida solamente como pureza, la verdad reclama una visión excluyente de las cosas, que sacrifica el orden finito, ya sea a través de un proceso de separación -como en el modelo dualista de la escuela Sānkhya y el Yoga clásico-, o degradando el mundo a mera e inexplicable ilusión proyectada sobre el uno absoluto - el modelo monista del Vedānta-, o a través de una aprehensión despierta, pero desvinculante, del orden temporal sin postular ninguna esencia detrás - el modelo del budismo-. Dicho de otro modo, la posibilidad de vivir sin inhibiciones ni ansiedad, y con ello vencer el sufrimiento en el aquí y el ahora, no en un plano transmundano, presupone como postulado teórico básico una visión de la persona y el cosmos como realidades al interior de una única conciencia omnipotente y dinámica. Este monismo incluyente radical es, pues, la única manera de aceptar las cosas sin excepción y tal como son. Leemos en otro pasaje de la misma obra: 
Cualquier sustancia, cualquier método, cualquier sitio y cualquier momento sirven para adorar [a la deidad], siempre y cuando ello haga reposar la conciencia [del adepto en su ser interior]. Así es, puede emplearse cualquier sustancia, ya sea sustancias comunes o prohibidas, pues lo que de verdad importa es que el adepto se deshaga de sus inhibiciones (śan்kā). Si aún es presa de éstas, entonces primero debe vencerlas [...] y para conseguirlo lo ideal es usar sustancias prohibidas y con ellas propiciar a las diosas que rigen sobre sus sentidos. El pilar que sostiene la prisión del samsara [y por lo tanto, el pilar del sufrimiento] es precisamente eso que llamo inhibición, flaqueza o contracción. Para trascender ese estado es necesario comprender que los mantras son simples sonidos, que cualquier sustancia [ya sea que se le juzgue como pura o impura] no es sino una combinación de los cinco elementos materiales, y que todos los seres son conciencia. ¿Cómo entonces puede hablarse de impureza? Y si no existe tal impureza, ¿por qué entonces todas esas inhibiciones? (Abhinavagupta, 1918-1938: 12.16-23).

Si la duda es el sello distintivo de una identidad contraída (sankkoca) o lánguida (glāni), agobiada por el peso de lo prohibido, con la mirada puesta en la pureza a costa de lo impuro, el rasgo distintivo del sabio es, en cambio, un estado de confianza plena y expansiva (vikāsa), que vuelve innecesarios el rechazo y el estigma como respuesta al samsara, apostando en cambio por un control vindicativo. Esto significa que para Abhinavagupta es posible abrazar las fuerzas de la existencia en el acto mismo de afirmarlas como la expresión libre del poder creador de la deidad. Esta afirmación liberadora descansa en una experiencia de totalidad incluyente en la que tiene cabida lo que otros consideran impuro. La absorción contemplativa en la omnipresencia divina, por encima de las diferencias, es la nueva forma de transgresión, al punto incluso de que la transgresión in actu, el legado de los primeros iniciados tántricos, es ahora prescindible. Si lo que importa es el estado de unión contemplativa que induce una identidad sin inhibiciones, entonces basta establecerse en esa identidad para alcanzar dicho estado, sin entrar en conflicto con el status quo. Esta idea aparece resumida en un famoso dicho de la época, evocado por el propio Abhinavagupta (1918-1938: 4.251) también en su Tantrāloka: ortodoxo por fuera, heterodoxo puertas adentro.

En otros pasajes de esta obra, Abhinavagupta vuelve al tema explícitamente a la luz de las nociones de dualidad y no-dualidad. Por ejemplo: "La liberación es posible sólo superando este sistema de inhibiciones. Es inalcanzable para quien aún vive bajo la influencia de una visión dualista" (Abhinavagupta, 
1918-1938: 15.593). Abhinavagupta entiende, pues, el sufrimiento como la debilidad o la falta de poder nacida del más mínimo indicio de dualidad. E1 sufrimiento se vence destruyendo su raíz, la ignorancia, como en casi todas las escuelas indias, pero en su caso esto significa desmantelar la propia noción de ignorancia hasta incluir en ella cualquier doctrina que prometa como antídoto sacrificar algún aspecto de la realidad, cualquier postura que no esté dispuesta a hacerse responsable de la realidad - con su enfermedad, vejez y muerte, para usar la fórmula budista - , en la tentativa de huir por el sendero de la pureza. En suma, el sujeto liberado "no es tal porque haya abolido el mundo de la manifestación, sopor del que finalmente ha despertado", como quieren las filosofías erigidas sobre el ideal de pureza y su corolario necesario, la inhibición, "sino porque ha aprendido a vivir ese mundo como la forma real en que se manifiesta libremente la divinidad" (Torella, 2011: 18-19).

\section{A manera de conclusión}

Podríamos decir, entonces, que la apuesta marginal de los primeros iniciados tántricos cobra con Abhinavagupta la forma de un llamado a abandonar cualquier victimismo y, por el contrario, a hacernos cargo del drama del samsara hasta las últimas consecuencias, lo que, una vez más, equivale a decir que la verdadera no dualidad (advaita) sólo puede alcanzarse no al margen sino en el samsara, a condición de que éste sea vivido sin inhibiciones (śan்khā), es decir, como la manifestación de una misma conciencia, la nuestra propia, también en lo impuro, en lo atroz y en lo terrible, hasta diluir la propia dicotomía puro-impuro.

A este respecto, en otro importante texto suyo, el Parātrīśikā-Vivaraṇa, un comentario a una breve escritura revelada, nuestro autor reitera el valor relativo de las fórmulas contra el sufrimiento que no cuestionan a fondo el sistema tradicional de valores ni las normas y los códigos canónicos, por definición erigidos sobre el ideal de pureza y su contrario, la impureza. En un gesto de concesión, sin embargo, parece considerar tales formulaciones como un mal necesario, en tanto que nos procuran un asidero y un sentido, no sin dejar de reiterar que la verdad última yace más allá de cualquier juicio subjetivo, y sólo entonces, podríamos agregar, más allá del sufrimiento: 
Toda inhibición representa un estado de contracción de la conciencia [...] Los sabios crearon dichas inhibiciones por el bien de los ignorantes con el fin de que tuvieran un orden social estable, y aunque es solo un constructo, se enraíza en ellos con tal profundidad que rinde toda clase de frutos. Ese mismo constructo asume además un sinfín de rostros que varían de una escritura a otra, de país en país, con diferentes nombres, de los cuales el dharma es solo uno de ellos. Sin embargo, cuando el individuo trasciende sus inhibiciones con una conciencia realmente no dual, consigue despojarse de la verdadera contaminación, la que imponen las restricciones sociales, y entra en el corazón de la deidad. (Abhinavagupta, 1985: 266-267)

Sirvan estas aleccionadoras palabras como conclusión de esta breve exploración sobre la singular postura de Abhinavagupta en torno al problema del sufrimiento, esperando que lo expuesto arroje nueva luz tanto sobre su pensamiento como sobre la dinámica de las tradiciones intelectuales y religiosas indias en temas cardinales como la finitud, el deseo y la liberación. Desde luego, la esperanza última, dados los aún incipientes esfuerzos para estudiar en nuestra lengua las filosofías no occidentales con sentido crítico y más allá de los estereotipos, es que esta reflexión contribuya a poner a un autor tan importante y original como Abhinavagupta en el radar no sólo de la filosofía india, sino de la indagación filosófica en general.

\section{Referencias bliográfícas}

ABhinaVAguPTA. (1918-1938). Tantrātoka (Madhusudan Kaul, Ed.). Nirnaya Sagar Press.

AbHinaVAgupta. (1985). Parātrīíikā-Vivarana (Raniero Gnoli, Ed.). Istituto Italiano per il Medio ed Estremo Oriente.

Bhagavadgītā (S. K. Belvalkar, Ed.). (1945). Bhandarkar Oriental Research Institute.

Mālinīvijaya Tantra (Madhusudan Kaul, Ed.) (1922). Research Department of Jammu and Kashmir State.

Olivelle, Patrick. (1998). "Caste and Purity: A Study in the Language of Dharma Literature". Contribution of Indian Sociology, 32(2), 189-216. https://doi. org/10.1177/006996679803200203

PADOUX, André. (1998). "Concerning Tantric Traditions". En Gerhard Oberhammer (Ed.), Studies in Hinduism II. Miscellanea to the Phenomenon of Tantras (9-20). Der österreichischen Akademie der Wissenschaften. 
Samyuttanikāya (Léon Feer, Ed.). (1884-1904). Pali Text Society.

SANDERSON, Alexis. (2009). "The Śaiva Age: The Rise and Dominance of Śaivism during the Early Medieval Period". En Shingo Einoo (Ed.), Genesis and Development of Tantrism (43-350). University of Tokyo.

The Tantra of Candamahāroṣana (Dharmachakra Translation Committee, Trad.). (2016). [En línea]. Recuperado de https://read.84000.co/translation/toh431. html

Torella, Raffaele. (2011). "Prólogo". En André Padoux, El Tantra (13-25). Kairós.

TORELla, Raffaele. (2015). "Purity and Impurity in Nondualistic Śaiva Tantrism". Studia Religiologica,48(2), 101-115. https://doi. org/10.4467/20844077SR.15.008.3554

Vijñana Bhairava Tantra (Traducción, estudio preliminar y comentarios de Óscar Figueroa) (2017). Kairós. 